\title{
A FORMAÇÃO INICIAL DE PROFESSORES DE QUÍMICA SOB O OLHAR DOS COORDENADORES DOS CURSOS
}

\author{
Roberta Guimarães CORRÊA ${ }^{1}$ \\ Rosebelly Nunes MARQUES ${ }^{2}$
}

Resumo: Apesar do reconhecimento da necessidade de mudanças e da produção constante de estudos sobre a formação inicial, os cursos de licenciatura ainda apresentam questões que precisam ser discutidas. Tais questões estão relacionadas à dificuldade de superar o déficit de professores da educação básica e também referentes ao tipo de formação oferecida nos cursos de licenciatura das Instituições de Ensino Superior (IES), que parece não atender as atuais demandas educacionais brasileiras. Este trabalho apresenta dados de uma pesquisa de natureza qualitativa realizada junto à coordenadores de cursos de licenciatura em Química de sete instituições de ensino superior do estado de São Paulo. Apesar das diferentes realidades institucionais que compuseram o trabalho de pesquisa, a dificuldade de efetivamente contribuir com a formação de professores de Química é comum a todas às IES. Dificuldade de formação de novas turmas, evasão, a relação entre o bacharelado e a licenciatura e $o$ descompromisso dos docentes com a licenciatura fazem parte dos relatos dos coordenadores.

Palavras-chave: Licenciatura. Química. Coordenadores de curso.

\section{INTRODUÇÃO}

A redefinição do papel formador das instituições escolares está presente no discurso de autores que refletem a educação escolar em um panorama global e também nos documentos legais que orientam as práticas pedagógicas dentro das escolas de educação básica brasileiras. A Lei de Diretrizes e Bases da Educação Nacional - LDB (BRASIL, 1996) destaca a formação para a cidadania que deverá possibilitar ao cidadão a capacidade de continuar aprendendo para adaptar-se com flexibilidade às diversas situações do cotidiano e do mundo do trabalho. A formação ética, o desenvolvimento da autonomia e do pensamento crítico também são objetivos da educação escolar. Gatti (2009) também destaca a importância da formação ética, social e ainda acrescenta a necessidade de se considerar à formação afetiva no contexto educativo. Essa diversidade de dimensões formativas soma-se ao compromisso da universalização do acesso ao

\footnotetext{
${ }^{1}$ IFSP - Instituto Federal de Educação, Ciência e Tecnologia de São Paulo. Catanduva - SP - Brasil. 15808-305 - roberta.guicorrea@gmail.com.

2 Departamento de Economia, Administração e Sociologia LES/ESALQ. USP - Universidade de São Paulo. Piracicaba - SP - Brasil. 13418-900 - rosebelly@gmail.com.
} 
ensino e a ampliação da escolaridade, que são tratados no Plano Nacional da Educação PNE (BRASIL, 2014), que entrou em vigência em 2014.

Considerando à ampliação da escolaridade e a necessidade de mudanças das práticas educativas, o PNE destaca como estratégica para a melhoria da educação nacional a formação dos professores. Esse conceito de formação está associado à ideia que ensinar muito além da transmissão de um conhecimento especializado do professor para o estudante, como afirmam Roldão (2007) e Roldão et al. (2009). Para que a formação do sujeito possa efetivamente contribuir para a sua inserção e ação na sociedade atual, o professor deve atuar de forma a possibilitar que seu estudante se aproprie de conhecimentos, ou seja, a ação do professor deve orientar e facilitar a interação do estudante com o currículo trabalhado em sala de aula (ROLDÃO, 2007).

Popkewitz (1997) também discute o papel do professor na formação dos sujeitos e ressalta a importância de uma prática profissional responsável, autônoma e consciente da influência política, social e econômica que compõe a escola e o seu currículo. Para a atuação nessa realidade, fala-se de um profissional altamente competente, não só tecnicamente, mas também intelectualmente preparado para se inserir de maneira consciente e crítica nesse sistema. Quando se fala em preparação, em formação para a docência, os cursos superiores, tanto de pedagogia quanto de licenciatura, compreendem um momento importante do desenvolvimento do profissional do professor. Trata-se de um momento formativo porque a formação é compreendida a partir do modelo da racionalidade prática que considera o desenvolvimento profissional "[...] um processo de desenvolvimento para a vida toda". (MIZUKAMI et al., 2002, p.13).

Considerando a formação de professores de Química para a atuação na educação básica, os cursos de licenciatura, de graduação plena, oferecidos em universidades e institutos superiores de educação, tem sido foco de muitas análises e também de muitas reestruturações que visam à revisão de concepções de formação e, ao mesmo tempo, a melhoria dos cursos. Além das diretrizes e pareceres publicados que tratam da formação do professor de maneira mais abrangente, como os Pareceres CNE/CP $\mathrm{n}^{\circ}$, de 8 de maio de 2001 (BRASIL, 2001a), CNE/CP n 28 (BRASIL, 2001b) e as resoluções $\mathrm{CNE} / \mathrm{CP} \mathrm{n}^{\circ} 1$ publicada em 18 de fevereiro de 2002 (BRASIL, 2002a) e CNE/CP n 2 (BRASIL, 2002b), duas normativas tratam especificamente dos cursos de licenciatura em Química: as Diretrizes Curriculares Nacionais para os Cursos de Química e o parecer CNE/CES n. ${ }^{\circ} 1.303$ (BRASIL, 2001c) e a resolução CNE/CES nº (BRASIL, 2002c). As normativas citadas sinalizam mudanças na formação de professores que já 
eram fomentadas por estudiosos e pesquisadores brasileiros nas décadas de 60 e 70 (GATTI 2011). A necessidade de repensar a organização curricular dos cursos e também de aprofundar a abordagem de conhecimentos, saberes e competências que norteiam a ação profissional do professor, gerou uma intensificação nos estudos e reflexões sobre a reestruturação das práticas nos cursos de formação inicial e também sobre as concepções pedagógicas e epistemológicas que definem as práticas e também a ação dos formadores (ESCHEVERRÍA; ZANON, 2010).

Apesar do reconhecimento da necessidade de mudanças e da produção constante de estudos sobre a formação inicial, os cursos de licenciatura ainda apresentam questões que precisam ser discutidas. Um dos motivos destacados por Gatti (2011) relaciona-se à estrutura das instituições que dificultam as mudanças dos processos formativos. Somado a isso está o professor universitário que, na maioria dos casos, ainda não reconhece seu papel como formador de professores de Química e por isso não reflete sobre o impacto da formação que oferece aos futuros professores. Extrapolando a estrutura institucional e a realidade educacional brasileira, mais precisamente "[...] o déficit de, aproximadamente, 250 mil professores de matemática, Física, Química e Biologia no País” (PEREIRA, 2011, p.90) só aprofunda a preocupação com os cursos de formação, que apesar de terem se expandido, não estão conseguindo formar professores de Química para suprir tal demanda. A necessidade de suprir essa demanda tem levado à expansão dos cursos de licenciatura, que tem sido fonte de críticas de pesquisadores e estudiosos que questionam a capacidade formadora dessas instituições (MALDANER, 2010).

É dentro desse contexto, de avanços e retrocessos sobre a formação inicial de professores de Química e de problemas relacionados ao déficit de professores e também referentes à formação para as atuais demandas educacionais, que este trabalho apresenta dados de uma pesquisa de natureza qualitativa realizada com coordenadores de cursos de licenciatura em Química de instituições de ensino superior do estado de são Paulo. Os relatos apresentados neste sobre trabalho pelos coordenadores versam sobre as características gerais dos cursos de licenciatura e sobre o perfil dos ingressos e egressos de seus cursos.

\section{Metodologia da pesquisa}

O trabalho apresenta os resultados de uma pesquisa qualitativa realizada em 7 instituições de ensino superior (IES) do estado de São Paulo entre o segundo semestre 
de 2013 e o primeiro semestre de 2014. Dentre as instituições, duas são institutos federais, quatro são universidades e um centro universitário. Os coordenadores dos cursos de licenciatura em Química foram entrevistados a partir de um roteiro semiestruturado com questões que procuraram identificar características dos cursos e também levantar as opiniões sobre o perfil dos ingressos e egressos de seus cursos. As entrevistas tiveram o áudio gravado e depois foram submetidas à transcrição. As entrevistas transcritas foram submetidas à análise de conteúdo qualitativa com a criação de categorias (LANKSHEAR; KNOBEL, 2008). O objetivo da análise de conteúdo, como ressaltam Lankshear e Knobel (2008), é reduzir a complexidade dos textos para torná-los passíveis de análise e construção de significados.

\section{Resultados}

Sete instituições de ensino superior (IES) do estado de São Paulo participaram deste trabalho. A Tabela 1 apresenta a identificação de cada curso, classificação acadêmico administrativa, categoria administrativa e a modalidade dos cursos.

Tabela 1 - Identificação das IES participantes da pesquisa

\begin{tabular}{|c|c|c|c|}
\hline $\begin{array}{c}\text { Identificação } \\
\text { do Curso }\end{array}$ & $\begin{array}{c}\text { Classificação Acadêmico- } \\
\text { Administrativa }\end{array}$ & $\begin{array}{c}\text { Categoria } \\
\text { Administrativa }\end{array}$ & $\begin{array}{c}\text { Modalidade } \\
\text { Curso }\end{array}$ \\
\hline UF1 & Universidade Federal & Pública & Presencial \\
\hline UE1 & Universidade Estadual & Pública & Presencial \\
\hline UE2 & Universidade Estadual & Pública & Presencial \\
\hline UN1 & Universidade & Privada & Presencial \\
\hline CE1 & Centro Universitário & Privada & Presencial \\
\hline IF1 & Instituto Federal & Pública & Presencial \\
\hline IF2 & Instituto Federal & Pública & Presencial \\
\hline
\end{tabular}

Fonte: Corrêa (2015).

Todos os cursos são oferecidos na modalidade presencial, mas diferem quanto à categoria administrativa e também quanto à classificação acadêmico-administrativa. Tais diferenças são relevantes para a discussão sobre os perfis gerais dos cursos pois refletem características institucionais relacionadas à autonomia e também com relação a sua atuação no ensino, pesquisa e extensão. De acordo com dados disponibilizados no sítio do MEC, a Universidade é definida na Lei de Diretrizes e Bases - LDB (BRASIL, 
1996) e corresponde à instituição acadêmica pluricurricular que conta com a pesquisa institucionalizada e possui autonomia para criar cursos, expedir diplomas, determinar currículos, definir número de vagas, firmar acordos, desde que respeite as legislações vigentes e a norma constitucional. Os Centros Universitários também correspondem à instituições pluricurriculares que apresentam estrutura semelhante à Universidade, porém não estão definidas na $\mathrm{LDB}$ e não apresentam como requisito a pesquisa institucionalizada. Os Institutos Federais (IFs): são voltados à formação técnica, com capacitação profissional em áreas diversas. Oferecem ensino médio integrado ao ensino técnico, cursos técnicos, cursos superiores de tecnologia, licenciaturas e pós-graduação. Somada a diversidade de papeis e compromissos institucionais está a categoria administrativa. IES públicas e privadas compõem duas realidades com relação à necessidade de se manterem competitivas frente ao elevado número de IES que oferecem formação superior.

A busca de outras informações das IES participantes foi realizada através da consulta ao sítio do e-MEC (BRASIL, 2012), de responsabilidade do Ministério da Educação (MEC), que disponibiliza, através de mecanismos automáticos de busca, informações sobre os cursos disponíveis, processos de abertura, autorização, credenciamento e recredenciamento das IES de todo o Brasil. A Tabela 2 apresenta o ano de inicio de funcionamento dos cursos, a carga horária total, número de vagas autorizadas e tempo de integralização dos cursos.

Tabela 2 - IES - Ano inicial de funcionamento do curso, carga horária total e vagas a autorizadas

\begin{tabular}{|c|c|c|c|c|}
\hline $\begin{array}{c}\text { Identificação } \\
\text { do Curso }\end{array}$ & $\begin{array}{c}\text { Funcionamento do } \\
\text { Curso }\end{array}$ & $\begin{array}{c}\text { Carga Horária } \\
\text { Total do Curso }\end{array}$ & $\begin{array}{c}\text { Tempo de } \\
\text { Integralização }\end{array}$ & $\begin{array}{c}\text { Vagas } \\
\text { Autorizadas }\end{array}$ \\
\hline UF1 & 2000 & $3090 \mathrm{~h}$ & 10 semestres & 30 \\
\hline UE1 & 2003 & $3195 \mathrm{~h}$ & 10 semestres & 40 \\
\hline UE2 & 2012 & $3255 \mathrm{~h}$ & 6 semestres & 10 \\
\hline UN1 & 2004 & $2822 \mathrm{~h}$ & 8 semestres & 40 \\
\hline CE1 & 2000 & $2833 \mathrm{~h}$ & 6 semestres & 70 \\
\hline IF1 & 2008 & $2103 \mathrm{~h}$ & 8 semestres & 80 \\
\hline IF2 & 2011 & $3070 \mathrm{~h}$ & 8 semestres & 80 \\
\hline
\end{tabular}

Fonte: Elaboração própria. 
O curso UE2 chama a atenção pela alta carga horária do curso (3255 h) e o tempo integralização anunciado (6 semestres), porém, cabe ressaltar que nesta instituição o aluno ingressa no curso de graduação em Química e ao final do primeiro ano do curso, opta pela licenciatura em Química ou pelo bacharelado em Química Ambiental. Dessa forma, a carga horária mencionada considera os quatro anos do curso e o tempo de integralização só considera o tempo de formação específico do curso de licenciatura. Caso semelhante acontece com o curso IF1 onde a carga horária só considera a formação do licenciado em Química e não considera a formação comum que é ofertada junto ao curso de Ciências Biológicas.

A Tabela 2 apresenta informações gerais sobre os cursos que nos fornecem poucas informações que melhor caracterizem os perfis institucionais, mas, que em conjunto com os relatos dos coordenadores de curso, podem contribuir para conhecer melhor tais perfis e o compromisso com a formação inicial de professores. As respostas dos coordenadores frente aos questionamentos nos proporcionaram a construção de categorias que trazem à tona pontos de discussão referentes à formação de novas turmas, o envolvimento do corpo docente e com relação ao perfil de ingressos e egressos. A formação de novas turmas apresenta-se com um desafio tanto para as instituições particulares quanto para as públicas. No caso das instituições particulares (CE1 e UN1), a dificuldade na formação de novas turmas acaba levando as instituições a adotarem estratégias para que possam continuar competitivas, como pode ser notado no relato do coordenador do CE1 sobre a necessidade de mudanças na duração do curso: "[...] verificaram que cabiam em 3 anos em instituição privada, então nós começamos a perceber a concorrência na região, todo mundo fazendo os cursos em 3 anos." (Coordenador CE1). O mesmo coordenador também destaca à implementação de uma complementação na área industrial como destaque do curso frente aos demais oferecidos na região: “[...] apesar de nosso curso ser de licenciatura né, nós temos uma complementação extra curricular na área industrial." (Coordenador CE1). A mesma pressão para a manutenção da competitividade também é sentida na UN1:

[...] se pela questão mercadológica valeria a pena oferecer um curso de 3 anos, em termos de que a gente pode oferecer de melhor ao nosso estudante, 4 anos seria o tempo adequado para cumprir a mesma carga horária... é um dos grandes problemas que nos temos para a área de licenciatura, nós precisamos oferecer essa formação, mas a questão financeira tem nos sufocado. (Coordenador UN1). 
Nas IES públicas a queda na procura pelo curso de licenciatura em Química também é sentida nas IES públicas. Dois relatos de coordenadores, da UF1 e IF1, destacam a dificuldade no preenchimento de vagas ofertadas para formação de turmas: “[...] nessa entrada agora, o ano passado foi um pouquinho crítico, esse maior ainda, esse semestre foi muito [...] esse ano foi muito mais crítico o número de chamadas que teve para completar turma" (Coordenador UF1) e "A nossa procura eu classificaria como não sendo grande não, porque são 40 vagas que são ofertadas por ano, todo início de ano [...] Quando era vestibular no início, tipo 2009, 2010, que tinha vestibular ainda, a concorrência era bem baixas." (Coordenador IF1). A diminuição pela procura de cursos de licenciatura é discutida por Gatti (2011) que destaca como possíveis fatores à baixa atratividade da carreira docente e também à própria estrutura dos cursos, que ela denomina como "[...] dinâmica curricular pouco motivadora." (GATII, 2011, p.73). A estrutura curricular de tais cursos tem refletido de alguma forma, apesar de muitas vezes não admitido pelos próprios coordenadores e professores, nos índices de evasão que são consideráveis nos cursos de licenciatura em Química e que foi destacado na fala da coordenadora da UF1: “[...] preenchemos na primeira semana da primeira chamada algumas pessoas, mas em poucas semanas existe uma evasão muito grande. A gente tem observado que metade dos alunos que entram sai rápido, até o final do primeiro semestre". A associação dos índices de evasão à organização curricular pode ser justificada por conta de inabilidade dos cursos em trabalhar com um perfil de ingresso diferente. A coordenadora da UE2 ressalta o que considera uma nova realidade: "Nós percebemos alunos cada vez mais novos, chegando à universidade e é um choque de realidade para eles porque saem de casa, tem que se virar sozinhos, então uma certa imaturidade, eles perdem o referencial de disciplina para estudo". Além do "choque de realidade" apontado pela coordenadora da UE2 também foram identificados relatos relacionados ao desempenho dos licenciandos e à falta de conhecimento necessário ao prosseguimento dos estudos nas IES.

[...] senti uma queda um pouco mais acentuada no desempenho dos alunos e esse ano com $50 \%$ vindo da escola pública está sendo mais difícil, eu andei conversando com as professoras de química geral e elas estão me dizendo que é um desestímulo assim dos alunos. (Coordenador UF1).

Enquanto a estrutura curricular não passa por rediscussões mais profundas para que possa adequar-se ao perfil de ingresso dos cursos de licenciatura, o corpo docente e 
a própria instituição, podem estar afastando os graduandos de uma possível atuação como docentes da educação básica. A visão negativa da licenciatura foi observada no discurso da coordenadora do curso UE1: "Ah, negativa. Eles não veem com bons olhos formação de professor. Quando eu discuto sempre no conselho, na reestruturação mesmo, ah, vamos terminar com o curso de licenciatura, vamos deixar só o bacharelado". O corpo docente desta instituição, conforme relato da coordenadora do curso, foca em uma formação inicial que de distancia da licenciatura e se aproxima do bacharelado. Essa relação de aproximação e de comparação ao curso de bacharelado em Química pode ser identificado no relato da coordenadora da UE1:

[...] ah o importante é iniciação científica, tem que formar pesquisador, tem que ir para o laboratório pesquisar. Sempre as discussões acabam sendo norteadas por isso, a maioria não vê com bons olhos a licenciatura, isso é claro, eles querem pesquisa, pensar na pós-graduação, só bacharelado, indústria. (Coordenador UE1).

A comparação entre os cursos de licenciatura e bacharelado destacada nos relatos mencionados apresenta-se como uma justificativa da posição inferior que a licenciatura em Química ocupa se comparada ao bacharelado (MALDANER, 2010). Essa diferença de status esta relacionada a menor relação candidato-vaga e também à matriz curricular, que é considerada inadequada para a preparação do Químico, principalmente aquele que atuará na pesquisa acadêmica. Esses relatos sobre a inadequação da formação oferecida nos cursos de licenciatura ecoam nas Universidades, que têm a pesquisa institucionalizada. A presença marcante da pesquisa institucional repercute em um forte envolvimento dos graduandos com atividades realizadas em laboratórios de pesquisa científica de áreas específicas da Química (Orgânica, Inorgânica, Físico-Química, Analítica), que muitas vezes é formalizado à partir de uma iniciação científica remunerada (CORRÊA; MARQUES, 2014). Esta aproximação com a pesquisa científica nas tradicionais áreas da Química, acaba distanciando muitos licenciandos da docência. Gatti (2011) destacada que esta vivência com a pesquisa científica na graduação leva os licenciandos a criarem um maior vínculo com as áreas específica de conhecimento das Ciências. Tal vínculo, como foi identificado por Corrêa e Marques (2014), leva os licenciandos em Química a mencionarem à carreira acadêmica como perspectiva profissional, inclusive destacando o desejo de atuarem como professores da educação superior. Esta perspectiva sobre o perfil dos egressos de seus cursos foi citada por alguns coordenadores: "[...] então o aluno com uma boa 
formação em química é capaz de prestar a prova e cursar, fazer a sua pós-graduação e continuar a carreira acadêmica" (Coordenador UE2), "[...] a maioria dos alunos vai para a pós-graduação aqui, não tem jeito mesmo, quase todos os alunos têm como opção ao final do seu curso a pós-graduação pela força que a pós-graduação tem no departamento". (Coordenador UF1).

Outro elemento do perfil do egresso relaciona-se ao conhecimento em Química, ou seja, a importância dada a este conhecimento para o exercício da docência ou para a atuação profissional em outra área relacionada à Química: "[...] esses alunos terão plenas condições de atuar na educação básica com uma formação bastante sólida com química" (Coordenador UE2), "[...] a primeira coisa que a gente espera que o professor tenha ao sair daqui, é claro, ninguém aprende tudo, mas que pelo menos saiba química [...]". (Coordenador UN1).

\section{Algumas considerações}

As diferentes realidades institucionais que compuseram o trabalho de pesquisa apresentam como problema comum a dificuldade de efetivamente contribuir com a formação de professores de Química que levarão à diminuição do déficit de professores apontado no trabalho de Pereira (2011). As reflexões sobre os motivos de tais dificuldades passam por um ponto fundamental da docência na educação básica, a desvalorização da profissão docente. Porém, a baixa atratividade da carreira não pode ser única responsável pelo reduzido número formados que decidem exercer a docência. As IES, com seus compromissos institucionais e com a necessidade de manter-se competitiva, acaba levando à formação de um profissional que se identifica muito pouco com a docência no ensino fundamental e médio. Mesmo considerando a formação inicial como um dos momentos da trajetória formativa do professor, esse momento formativo é de fundamental importância para a revisão de concepções sobre a docência e para a construção da identidade docente. Os cursos de licenciatura precisam ser considerados locais privilegiados para a formação específica em Química, mas também como locais para a reflexão sobre ensinar Química e sobre a docência enquanto profissão carregada de valores políticos e éticos.

\section{CHEMISTRY TEACHER INITIAL FORMATION UNDER THE EYE OF THE COORDINATORS OF THE COURSES}


Abstract: Despite the recognition of the need for change and the constant production of studies on initial formation, the degree courses still have questions that need to be discussed. These issues are related to the difficulty to overcome the lack of teachers in basic education and the type of formation offered in undergraduate courses, which does not seem to meet the current Brazilian educational demands. This paper presents data from a qualitative study conducted with coordinators of seven higher education institutions in the state of São Paulo. Despite the different institutional realities presented in this work, the difficulty of effectively contribute to the formation of chemistry teachers is common to all the institutions. Lack of interest in initial formation teacher's courses, evasion problems, relationship between the initial formation of chemical teachers and chemistry's professionals and the lack of commitment of teachers marked the reports of the coordinators of the courses.

Key words: Inicial formation teachers. Chemistry. Course coordinators.

\section{REFERÊNCIAS}

BRASIL. Ministério da Educação. e-MEC. Brasília: MEC, 2012. Disponível em: <http://emec.mec.gov.br/>. Acesso em: 10 out. 2013.

Lei n. 9.394, de 20 de dezembro de 1996. Lei de diretrizes e bases da educação nacional. Brasília: MEC, 1996. Disponível em: <http://portal.mec.gov.br/arquivos/pdf/ldb.pdf >. Acesso em: 10 out. 2013.

Parecer CNE/CES n.1.303, de 06 de novembro de 2001. Diretrizes Curriculares Nacionais para os Cursos de Química. Brasília: MEC, 2001c. Disponível em: < http://portal.mec.gov.br/cne/arquivos/pdf/CES1303.pdf> Acesso em: $10 \mathrm{dez} .2011$.

Parecer CNE/CP n.9, de 8 de maio de 2001. Diretrizes Curriculares Nacionais para a Formação de Professores da Educação Básica, em nível superior, curso de licenciatura, de graduação plena. Brasília: MEC, 2001a. Disponível em: http://portal.mec.gov.br/cne/arquivos/pdf/009.pdf > Acesso em: 10 dez. 2011

Parecer CNE/CP n. 28, de 2 de outubro de 2001. Dá nova redação ao Parecer CNE/CP 21/2001, que estabelece a duração e a carga horária dos cursos de Formação de Professores da Educação Básica, em nível superior, curso de licenciatura, de graduação plena. Brasília: MEC, 2001b. Disponível em: < http://portal.mec.gov.br/cne/arquivos/pdf/028.pdf> Acesso em: 10 dez. 2011.

Planejando a próxima década: conhecendo as 20 metas do plano nacional de educação. Brasília: MEC, 2014.

Resolução CNE/CES n.8, de 11 de março de 2002. Estabelece as Diretrizes Curriculares para os cursos de Bacharelado e Licenciatura em Química. Brasília: MEC, 2002c. Disponível em: < http://portal.mec.gov.br/cne/arquivos/pdf/CES082002.pdf> Acesso em: $10 \mathrm{dez} .2011$. 
Resolução CNE/CP n.1, de 18 de fevereiro de 2002. Diretrizes Curriculares Nacionais para a Formação de Professores da Educação Básica, em nível superior, curso de licenciatura, de graduação plena. Brasília: MEC, 2002a. Disponível em: < http://portal.mec.gov.br/seesp/arquivos/pdf/res1_2.pdf> Acesso em: 10 dez. 2011.

Resolução CNE/CP n.2, de 19 de fevereiro de 2002. Institui a duração e a carga horária dos cursos de licenciatura, de graduação plena, de formação de professores da Educação Básica em nível superior. Brasília: MEC, 2002b. Disponível em: < http://portal.mec.gov.br/cne/arquivos/pdf/CP022002.pdf> Acesso em: 10 dez. 2011.

CORRÊA, R. G. Formação Inicial de Professores de Química: discursos, saberes e práticas. 2015. 165 f. Tese (Doutorado em Ciências) - Centro de Ciências Exatas e de Tecnologia, Universidade Federal de São Carlos, São Carlos, 2015.

CORRÊA, R.G.; MARQUES, R. N. Formação inicial de professores de química: motivos, perspectivas e percepções de licenciandos em química. Anais do 2 Congresso Nacional de Professores e 12 Congresso Estadual sobre Formação de Educadores. Águas de Lindóia - SP. 2014.

ECHEVERRÍA, A. R.; ZANON, L. B. Formação superior em química no Brasil: práticas e fundamentos curriculares. Ijuí: Unijuí, 2010.

GATTI, B. A. Formação de professores: condições e problemas atuais. Revista Brasileira de Formação de Professores, Cristalina, v.1, n.1, p.90-102, mai. 2009.

Licenciaturas: características institucionais, currículos e formação profissional. In: PINHO, S. Z. (Org). Formação de educadores: dilemas contemporâneos. São Paulo: Ed. da UNESP, 2011. p.71-88.

LANKSHEAR, C.; KNOBEL, M. Pesquisa pedagógica: do projeto à implementação. Porto Alegre: ARTMED, 2008.

MALDANER, O. A. Prefácio. In: ECHEVERRÍA, A.R; ZANON, L. B. Formação superior em química no Brasil: práticas e fundamentos curriculares. Ijuí: Unijuí, 2010. p.9-16.

MIZUKAMI, M. G. N. et al. Escola e aprendizagem da docência: processos de investigação de formação. São Carlos: Ed. da UFSCar, 2002.

PEREIRA, J. E. D. Sinais da crise das licenciaturas no Brasil. In: PINHO, S. Z. Formação de educadores: dilemas contemporâneos. São Paulo: Ed. da UNESP, 2011. p.89-102.

POPKEWITZ, T. S. Profissionalização e formação de professores: algumas notas sobre a sua história, ideologia e potencial. In: NÓVOA, A. (Org.). Os professores e a sua formação. 3.ed. Lisboa: Dom Quixote, 1997. p.35-50.

ROLDÃO, M. C. Função docente: natureza e construção do conhecimento profissional. Revista Brasileira de Educação, Campinas, v.12, n.34, p.94-103, jan./abr. 2007. 
et al. O conhecimento profissional dos professores: especificidade, construção

e uso da formação ao reconhecimento social". Revista Brasileira de Formação de Professores, Cristalina, v.1, n.2, 2009. 